\title{
TRIBUNAL PENAL INTERNACIONAL: A DIFERENÇA DA CONCEPÇÃO TEÓRICA E ATUAÇÃO PRÁTICA DO BRASIL EM COMPARAÇÃO COM OS EUA
}

Tatyana Scheila Friedrich ${ }^{1}$

O "Estatuto de Roma", tratado internacional que criou o Tribunal Penal Internacional (TPI), foi assinado em 1988 em Roma e entrou em vigor no dia $1^{\circ}$. de julho de 2002, após o sexagésimo depósito de instrumento de ratificação. Foi um marco na história do direito internacional pois pela primeira vez se estabeleceu uma corte judicial internacional para julgar criminosos de guerra e perpetradores de genocídio e crimes contra a humanidade, quando não forem julgados por seus tribunais nacionais. Finalmente 0 mundo se mostrou pronto para criar um tribunal de caráter permanente e se livrar dos tribunais de exceção, criados pelos vencedores nos períodos posteriores às guerras ou pelo Conselho de Segurança da ONU para julgar situações localizadas, como ocorreu com os Tribunais da ex-lugoslávia, de Ruanda e de Serra Leoa.

São 128 artigos que compõem o texto do Estatuto de Roma, divididos nas 13 partes seguintes: Parte I: Estabelecimento do tribunal (arts. 1-4); Parte II: Jurisdição, admissibilidade e direito aplicável (arts. 5-21); Parte III: Princípios gerais do direito penal (arts. 22-33); Parte IV: Composição e administração do tribunal (arts. 34-52); Parte V: Investigação e ajuizamento (arts. 53-61); Parte VI: O julgamento (arts. 62-76); Parte VII: Penas: (arts. 77-80); Parte VIII: Apelação e revisão (arts. 81-85); Parte IX: Cooperação internacional e assistência judicial (arts. 86-102); Parte X: Execução (arts. 103-111); Parte XI: Assembléia de Estados (art. 112); Parte XII: Financiamento (arts. 113-118); Parte XIII: Cláusulas Finais (arts. 119-128).

O artigo 5o prevê a competência do TPI para julgar o crime de genocídio, crimes contra a humanidade, crimes de guerra e agressão. $O$

\footnotetext{
1 Professora de Direito Internacional Privado na Universidade Federal do Paraná. Coordenadora Docente do Núcleo de Estudos em Direito Internacional, da mesma universidade.
}

Revista Brasileira de Direito Internacional, Curitiba, v.1, n.1, jan./jun.2005 
genocídio, segundo no artigo 6ํㅡㄹ caracteriza-se pela intenção de destruir, em todo ou em parte, um grupo nacional, étnico, racial ou religioso, através do assassinato de seus membros, produção de sérios danos corporais e mentais a seus membros, imposição de condições de vida que provoquem, total ou parcialmente, sua destruição física; imposição de medidas de controle de natalidade a estes grupos e transferência forçada de crianças deste grupo a outros grupos.

Os crimes contra a humanidade, previstos no artigo $7^{\circ}$, significam 0 ataque direto contra qualquer população civil, com intenção de assassinato, extermínio, escravização, deportação ou transferência forçada; aprisionamento ou outra severa privação do direito de liberdade em violação a regras fundamentais de direito internacional; tortura; rapto, escravização sexual, prostituição forçada, esterilização forçada e demais graves violências sexuais; perseguição política, racial, étnica, nacional, cultural ou religiosa contra grupos ou a coletividade; desaparecimento de pessoas; crime de segregação racial (apartheid) e outros crimes intencionais que causem grande sofrimento, danos corporais, mentais ou à saúde física das vítimas.

O TPI também tem competência para julgar crimes de guerra, em particular quando cometidos como parte integrante de um plano ou de uma política ou como parte de uma prática em larga escala desse tipo de crimes, assim tipificados no artigo 8:: a) As violações graves às Convenções de Genebra, de 12 de Agosto de 1949, a saber, qualquer um dos seguintes atos, dirigidos contra pessoas ou bens protegidos nos termos da Convenção de Genebra que for pertinente: i) Homicídio doloso; ii) Tortura ou outros tratamentos desumanos, incluindo as experiências biológicas; iii) $O$ ato de causar intencionalmente grande sofrimento ou ofensas graves à integridade física ou à saúde; iv) Destruição ou a apropriação de bens em larga escala, quando não justificadas por quaisquer necessidades militares e executadas de forma ilegal e arbitrária; v) $\mathrm{O}$ ato de compelir um prisioneiro de guerra ou outra pessoa sob proteção a servir nas forças armadas de uma potência inimiga; vi) Privação intencional de um prisioneiro de guerra ou de outra pessoa sob proteção do seu direito a um julgamento justo e imparcial; vii) Deportação ou 
transferência ilegais, ou a privação ilegal de liberdade; viii) Tomada de reféns. b) Outras violações graves das leis e costumes aplicáveis em conflitos armados internacionais no âmbito do direito internacional. Em relação a estas últimas, o Estatuto de Roma lista outros 26 tipos penais.

Em relação ao crime de agressão, o Estatuto de Roma estabelece a necessidade de criação, pela Assembléia dos Estados -Partes, de um dispositivo específico para disciplinar a definição e as condições sob as quais o TPI atuará na persecução desse crime, tendo em vista que não houve um consenso sobre a tipificação da agressão durante a Conferência de Roma.

O Brasil ratificou o Tratado de Roma, realizando o depósito do instrumento de ratificação no dia 20 de junho de 2002. Durante o processo de internalização do tratado, muito se questionou a respeito da constitucionalidade do artigo que trata do encaminhamento do cidadão brasileiro ao TPI, chegando alguns autores a entendê-lo como caso de extradição nacional, vetada pela própria Constituição Federal - CF. Trata-se, em verdade, de mera entrega do nacional tendo em vista que ele será enviado para julgamento em um Tribunal Internacional, ao qual o Brasil soberanamente aderiu. Não haverá extradição do nacional para ser julgado por corte de país estrangeiro, como requer 0 conceito.

Outra discussão importante ocorreu em torno do dispositivo que prevê a pena de prisão perpétua dentre aquelas que poderão ser aplicadas pelo Tribunal aos seus condenados. $O$ entendimento adotado perpassou pela identificação da proibição da prisão perpétua do artigo 50 da CF como uma restrição nacional,ou seja, uma garantia ao cidadão de que o juiz pátrio nunca irá infligir-lhe pena de prisão perpétua - ainda que seja permitido, na comutação da pena, que esta ultrapasse a idade que o condenado poderá viver.

Assim o Brasil resolveu sua relação com o TPI, adotando-o enquanto anseio da comunidade internacional e, através dele, propugnando pelo fim da impunidade aos grandes violadores de direitos humanos. Isso já estava reforçado pelo artigo $7^{\circ}$ do Ato das Disposições Constitucionais Transitórias, que estabelece: "O Brasil propugnará pela formação de um tribunal 
internacional dos direitos humanos." A Emenda Constitucional 45/05 apenas confirmou essa situação, evitando quaisquer questionamentos futuros, ao estabelecer que o quarto parágrafo do artigo $5^{\circ}$ (Dos direitos e deveres individuais e coletivos) passou a vigorar com a seguinte redação: "O Brasil se submete à jurisdição de Tribunal Penal Internacional a cuja criação tenha manifestado adesão."

Na semana de 3 a 7 de fevereiro de 2003 aconteceu em Nova York a primeira sessão oficial da Assembléia dos países membros do TPI, onde o Brasil, mais uma vez, demonstrou seu compromisso com o órgão internacional, através da eleição da desembargadora federal de São Paulo, Sylvia Steiner, como uma das juízas da corte. ${ }^{2}$

Em reunião anterior da Assembléia, havia sido decidido que 0 procedimento de votação asseguraria uma eqüidade de representação regional, de sistema legal e de gênero. Isso decorreu de inúmeras manifestações de Organizações Não-governamentais, que lutaram para afastar as escolhas políticas e optar-se pelos candidatos mais qualificados, através de um pleito legítimo e transparente, livre das costumeiras barganhas políticas e econômicas. Um grande avanço nessa questão do gênero foi 0 estabelecimento do requisito de votação mínima em 6 mulheres.

A escolha de Sylvia Steiner representou o acolhimento da tese que defende 0 aumento da participação das mulheres nos tribunais internacionais. Atualmente não há nenhuma mulher atuando como juíza no Tribunal Internacional para o Direito do Mar, apenas uma na Corte Internacional de Justiça, uma no Tribunal Penal Internacional para a ex-lugoslávia e três no Tribunal Penal Internacional para Ruanda.

Quanto ao TPI, seu próprio tratado institutivo prevê a competência para julgar uma série de crimes cometidos contra as mulheres, um motivo a mais para não as excluir do processo de julgamento. O citado artigo $8^{\circ}$, que trata dos crimes de guerra, inclui, por exemplo, "Cometer atos de violação, escravidão

2 Além da presença da Dra. Sylvia Steiner, o TPI ficou composto por outros 17 juízes, dentre os 43 indicados pelos Estados. Dos 43, 10 eram mulheres e 33 eram homens, sendo, do total, 8 vindos da América Latina e Caribe, 10 da África, 6 da Ásia, 12 da Europa Ocidental e 7 do Leste Europeu.

Revista Brasileira de Direito Internacional, Curitiba, v.1, n.1, jan./jun.2005 
sexual, prostituição forçada, gravidez forçada (limpeza étnica), esterilização forçada ou qualquer outra forma de violência sexual que constitua também uma violação grave do artigo 3 comum as quatro Convenções de Genebra." (art. 8, 2, e, vi)

A composição final do TPI reforça o amplo espaço que o Brasil vem adquirindo no cenário internacional, tendo em vista que possui juízes na maioria das cortes internacionais permanentes, como é o caso de Antonio Augusto Cançado Trindade, juiz da Corte Interamericana de Direitos Humanos e Vicente Marotta Rangel, juiz do Tribunal Internacional para o Direito do Mar. Vale lembrar que Francisco Rezek até recentemente era juiz da Corte Internacional de Justiça da Haia.

O TPI foi instaurado fisicamente em agosto de 2003, na cidade da Haia, mantendo-se, assim, a forte tradição da Holanda em matéria de Direito Internacional. Atualmente, mais de cem países já ratificaram o Tratado de Roma, o que tem gerado um ambiente de otimismo entre os teóricos e os militantes na área de direitos humanos. Mas ainda há muito a ser feito tendo em vista que poucos Estados elaboraram legislação doméstica para regulamentar a implementação interna do estatuto do TPI.

Durante seus primeiros anos de existência, as ações do TPI se concentraram na sua estruturação e na regulamentação de suas próprias atividades. Foram definidos o orçamento, as regras sobre procedimento e provas, os princípios determinantes para o acordo de sede com os Países Baixos e o acordo sobre privilégios e imunidades.

Como dito, também foram escolhidos os 18 juízes que compõem 0 quadro julgador e, além disso, o argentino Moreno Ocampo como promotor e o francês Bruno Cathala para exercer as funções de escrivão. No dia 15 de março de 2005, o TPI iniciou sua primeira atividade jurisdicional, através da realização de uma audiência preliminar, a portas fechadas, sobre a investigação dos crimes de guerra cometidos na República Democrática do Congo - RDC. Trata-se do procedimento regular na fase de investigação dos fatos, em que se procede a uma consulta entre os juízes e a Procuradoria sobre a proteção das testemunhas e das vítimas, além do tema do sigilo de 
documentos. Paralelamente, estão sendo estudados os crimes de guerra e crimes contra a humanidade perpetrados em países africanos, como Uganda, Darfur (Sudão) e República Centro-afriacana.

Em se tratando dos demais países, destaca-se a ausência de importantes atores do cenário internacional, como os Estados Unidos, Rússia, China e os Estados árabes. Dentre estes, a grande maioria chegou a assinar o Tratado mas apenas a Jordânia o ratificou.

Os EUA, sobretudo no governo Bush, têm se mostrado como os grandes opositores ao TPI. Chegaram a assinar o Estatuto de Roma em 31 de dezembro de 2000, no final do mandato de Bill Clinton, mas retrocederam ao retirar tal assinatura em 6 de maio de 2002. Além das inúmeras manifestações expressas contrárias à ratificação do tratado, o governo americano tem adotado três frentes de atuação para dificultar a consolidação e o progresso do TPI.

Inicialmente, os norte-americanos estão forçando países a realizarem acordos com os EUA com o objetivo de garantir imunidade para cidadãos americanos. Isso porque o Estatuto de Roma estabelece a obrigação dos Estados- partes de entregar ao TPI os indiciados que estejam em seu território, independentemente de serem nacionais ou estrangeiros. No entanto, dispõe em seu artigo 98, 2 que o Tribunal "não dará curso a uma solicitação de entrega em virtude da qual o Estado requerido deva atuar de forma incompatível com as obrigações que lhe imponham um acordo internacional (...)". Aproveitando essa brecha no tratado e levando em consideração que a maioria dos oficiais que participam de missões da ONU são de nacionalidade norte-americana, o governo de Washington passou a exigir dos países da comunidade internacional que assinassem acordos bilaterais (chamados de acordos sobre o artigo 98) com os EUA, comprometendo-se a não entregar americanos ao TPI. Vários países cederam às pressões e estima-se que atualmente mais de 50 Estados já celebraram os acordos bilaterais. Em relação aos países resistentes, os EUA utilizaram uma conhecida tática de intimidação: seu poderio econômico. Assim, a partir de 1/7/2003, programas de assistência militar, que englobam financiamento, educação e treinamento militar, 
destinados a determinados países estrangeiros, inclusive o Brasil, foram suspensos. Vale lembrar que alguns aliados tradicionais e os membros da OTAN foram isentos de tal represália. Apesar do impacto financeiro ser pequeno, a atitude do governo Bush demonstra sua real intenção de boicotar o TPI e impedir seu completo funcionamento, além de deixar claro sua pretensão de ser, ele próprio e não o TPI, o guardião da justiça mundial.

Além disso, internamente, o Congresso Norte-americano vem editando uma ampla legislação visando a proteger e evitar que membros das Forças Armadas sejam julgados pelo TPI, inclusive prevendo o uso da força na realização dessa tarefa. É o caso da "Lei sobre proteção de oficiais americanos" ("American Servicemembers Protection Act, 2002") que prevê, dentre outros dispositivos, a suspensão de ajuda militar a Estados que são partes do TPI e não assinaram o Acordo Bilateral com os EUA. Também não se pode olvidar que o documento "Estratégia de Segurança Nacional dos Estados Unidos da América", escrito pelo presidente George W. Bush em 17/09/2002 e enviado ao Congresso dos EUA em 20/09/2003, refere-se ao TPI. Trata-se do mesmo texto que formulou a denominada "Doutrina Bush", prevendo a realização de ataques armados preventivos dos Estados Unidos contra outros países e que embasou a invasão e dominação do Iraque em 2003, numa clara violação aos princípios do Direito Internacional e da Carta da ONU. Sua redação é bastante objetiva: "Tomaremos as medidas necessárias para assegurar que nossos esforços no sentido de honrar nossos compromissos de segurança global e proteger os americanos não sejam prejudicados pelas possíveis investigações, inquéritos ou processos a serem efetuados pelo Tribunal Penal Internacional (TPI), cuja jurisdição não se estende aos americanos, e a qual não aceitamos."

A terceira área de atuação norte-americana se concentra num ambiente que lhes é bastante favorável: o Conselho de Segurança (CS) da ONU. Em 2003 o CS expediu por unanimidade a Resolução 1422, que previa um período de 12 meses em que o TPI não poderia proceder a investigações e denúncias de pessoas nacionais de Estados que não são partes do TPI e que estejam envolvidas em qualquer missão de paz da ONU ou missões 
autorizadas por ela. Isso gerou a imediata aquisição de imunidade por parte de oficiais norte-americanos, que configuram a maioria dos participantes daquelas missões.

A fundamentação desse ato normativo está no artigo 16 do Estatuto de Roma, que estabelece: "Caso o Conselho de Segurança, de conformidade com uma resolução aprovada com base no disposto no Capítulo VII da Carta das Nações Unidas, peça ao Tribunal que suspenda por um prazo de 12 meses a investigação ou ajuizamento que tenha iniciado, o Tribunal procederá a essa suspensão. A petição poderá ser renovada pelo Conselho de Segurança nas mesmas condições".

Em geral, o artigo 16 era interpretado por internacionalistas como uma faculdade do CS para ser utilizada excepcionalmente e mediante casos concretos trazidos ao Tribunal quando este estivesse em funcionamento, sem configurar uma submissão de suas atividades à autorização prévia do CS.

Utilizando a faculdade prevista no final do citado artigo 16, a própria Resolução 1422 criou um mecanismo permitindo sua renovação, o que foi imediatamente utilizado pelos EUA. A primeira renovação, já em 2003, deu-se em sessão pública em que o CS aprovou a Resolução 1487. Naquela ocasião, a medida encontrou oposição da União Européia, tendo sido aprovada por 12 votos a favor e 3 abstenções - França, Alemanha e Síria. Apesar de ser um avanço em relação ao ano anterior, quando a votação foi de 15 votos a zero (depois das ameaças dos EUA de se retirarem de algumas missões), o resultado tem sua significação crítica, haja vista que os três países não tiveram coragem de utilizar seu poder de veto.

Os Estados Unidos pela primeira vez na história deixaram de indicar um juiz para compor uma corte mundial. Todas essas ações demonstram sua opção atual por uma linha política egoísta e prepotente, que desrespeita princípios fundamentais do Direito Internacional, como o da solução pacífica dos conflitos, e ignora o papel das Organizações Internacionais como responsáveis pela manutenção da paz e segurança internacionais. O Brasil tem muito a ensinar-Ihes.

Revista Brasileira de Direito Internacional, Curitiba, v.1, n.1, jan./jun.2005 